\title{
OPINIÃO/OPINION
}

\section{TRANSTORNO OBSESSIVO-COMPULSIVO E OS GÂNGLIOS DA BASE}

\author{
EURIPEDES CONSTANTINO MIGUEL FILHO*
}

\begin{abstract}
RESUMO - O transtorno obsessivo compulsivo (TOC), caracterizado por obsessões e compulsões, foi descrito com frequência aumentada $\mathrm{em}$ várias doenças que acometem primariamente of gânglios da base sugerindo que estas estruturas também estivessem acometidas no TOC. Os gânglios da base, que no passado se acreditava estarem implicados apenas no comportamento motor, são, na verdade, importantes em inúmeras outras funçōes psíquicas como o processamento de vivências cognitivas. Estudos recentes utilizando imagem de ressonância magnética mostraram tendência a diminuição do núcleo caudado em pacientes com TOC. De forma coerente, estudos com neuroimagem funcional, sugerem a implicação de um circuito cerebral envolvendo o córtex órbitofrontal, o giro cíngulo, o núcleo caudado e o tálamo na patofisiologia do TOC. Entre as diversas hipóteses formuladas a partir desses achados, especula-se que um déficit no funcionamento do núcleo caudado levaria a uma filtragem inadequada de preocupações que então estimulariam o córtex órbito-frontal a desencadear açōes adaptativas: as compulsões.
\end{abstract}

PALAVRAS-CHAVE: transtorno obsessivo-compulsivo, fisiolopatologia, gânglios da base, neuroanatomia.

\section{Obsessive-compulsive disorder and the basal ganglia}

SUMMARY - Obsessive-compulsive disorder (OCD), characterized by obsessions and compulsions, was described as more frequent in patients with primary lesions of the basal ganglia suggesting that these brain structures may be also altered in OCD. The basal ganglia, that were considered important only for the motor control, are known now as crucial for many other mental functions as processing of cognitive experience. Recent studies using magnetic resonance image have found a tendency for smaller caudate nucleus in patients with $\mathrm{OCD}$. Consistently, studies using functional neuroimaging suggest implication of a neurocircuit that includes the orbitalfrontal cortex, the cingulate cortex, caudate nucleus and thalamus in the pathophysiology of OCD. Among several hypotheses formulated to explain these findings, some authors speculated that a deficit of the caudate nucleus function would lead to inadequate filtering of worry inputs which would trigger the orbitalfrontal cortex to develop adaptative responses: the compulsions.

KEY WORDS: obsessive-compulsive disorder, pathophysiology, basal ganglia, neuroanatomy.

Inúmeras doenças neuropsiquiátricas têm como substrato neuroanatômico o acometimento dos gânglios da base. Entre estas citam-se o parkinsonismo pós-encefalítico, a coréia de Sydenham, a doença de Huntington e a síndrome de Tourette'. Surpreendentemente, o transtorno obsessivocompulsivo (TOC) ${ }^{2}$ - um transtorno neuropsiquiátrico crônico (Tabela), caracterizado por pensamentos, idéias ou imagens (obsessões) que surgem na consciência de forma inesperada e intrusiva

*Doutor em Medicina, Professor Coordenador do PROTOC do Instituto de Psiquiatria do Hospital das Clínicas da Faculdade de Medicina da Universidade de São Paulo (FMUSP). Aceite:22-agosto-1995. 
Tabela. Critérios diagnósticos do transtorno obsessivo-compulsivo segundo o DSM-IV.

A. Presença de obsessões ou compulsōes;

B. Reconhecimento de que os sintomas são excessivos ou sem sentido*;

C. Sintomas causam importante sofrimento, consomem tempo (mais de 1 hora/dia), ou interferem no funcionamento;

D. Sintomas não podem ser explicados apenas pela presença de um outro diagnóstico no Eixo I (ex.: transtorno alimentar).

*Especificar como poor insight; não considerar em crianças.

acompanhados por comportamentos repetitivos (compulsōes) com o objetivo de aliviá-las - foi descrito com frequência muito maior nestas doenças do que aquela esperada na população normal. Estas cifras aumentadas levantaram a hipótese de que os gânglios da base também estão acometidos no TOC!

Os principais componentes dos gânglios da base incluem o striatum, o globo pálido, a substância negra e o núcleo subtalâmico. O striatum é constituído do núcleo caudado e do putâmen. Os gânglios da base estão organizados em circuitos paralelos, nos quais regiões estriatais recebem projeções corticais, e emitem projeçōes, por sua vez, para o tálamo - antes, porém, passando pelo globo pálido e substância negra. Estas estruturas, que no passado acreditava-se serem importantes apenas no comportamento motor, sabe-se hoje, serem importantes para inúmeras outras funções psíquicas, como memória implícita e processamento de vivências cognitivas (pensamentos, idéias e imagens) ${ }^{3}$.

Recentemente, com o avanço dos métodos de neuroimagem de alta resolução, se tomou possível a visualização das estruturas cerebrais de modo mais refinado (ex.: imagem de ressonância magnética cerebral -IRM), bem como sua observação em funcionamento (ex.: tomografia por emissão de fóton único -SPECT; tomografia por emissão de pósitrons -PET; imagem de ressonância magnética funcional -fIRM). No que diz respeito ao TOC, estes métodos geraram novas hipóteses e um interessante modelo neuroanatômico. Por exemplo, estudos com neuroimagem estrutural descreveram uma tendência a diminuiçāo do núcleo caudad $0^{4}$. De forma coerente, estudos com neuroimagem funcional (SPECT, PET, fIRM) sugerem a implicaçāo de pelo menos quatro áreas na possível patofisiologia do TOC. Existem diversas teorias para explicar a participaçāo deste circuito no TOC. Entre elas encontra-se a de Baxter e colaboradores ${ }^{5}$. Eles acreditam que este circuito evoluiu nas diversas espécies animais no sentido de direcionar a atenção para ações necessárias e depois desencadear atitudes no sentido da preservação da espécie. Nesse sentido, eles acreditam que um déficit no funcionamento do núcleo caudado levaria a uma filtragem (repressão) inadequada de preocupaçōes (obsessões) originadas no córtex órbito-frontal. A ausência de inibição destes pensamentos pelo caudado tcria um papel de reforçar a importância daquela preocupação indevida, provocando então a necessidade do córtex órbito-frontal desencadear uma ação adaptativa: as compulsões. Esta teoria nos parece, no momento, ser o modelo mais interessante na compreensão da ncurocircuităria envolvida no TOC.

\section{REFERÊNCIAS}

1. Insel TR, Winslow JT. Neurobiology of obsessive-compulsive disorder. In Jenike MA, Baer L, Minichiello WE (eds). Obsessive-compulsive disorders: theory and management. St. Louis: Mosby Year Book, 1990, p $118-131$.

2. American Psychiatric Association. Diagnostic and statistical manual of mental disorders. Ed 4. Washington, DC: American Psychiatric Association, 1994.

3. Parent A, Hazrati L. Functional anatomy of basal ganglia: I. The cortico-basal ganglia-thalamo-cortical loop. Brain Res Rev 1995, 20:91-127.

4. Robison D, Wu H, Munne RA, Ashtari M, Alvir JMJ, Lerner G, Koreen A, Cole K, Bogerts B. Reduced caudate nucleus volume in obsessive-compulsive disorders. Arch Gen Psychiatry 1995, 52:323-398.

5. Baxter LR, Schwartz JM, Guze BH, Bergman K, Szuba MP. Neuroimaging in obsessive compulsive disorder: seeking the mediating neuroanatomy. In Jenike MA, Baer L, Minichiello WE (eds). Obsessive-compulsive disorders: theory and management. St. Louis: Mosby Year Book, 1990, p 167-188. 